\title{
Clonoamide, a new inhibitor of sterol $O$-acyltransferase, produced by Clonostachys sp. BF-0131
}

\author{
Keisuke Kobayashi $^{1,4}$, Nobuaki Tsukasaki ${ }^{2,4}$, Ryuji Uchida ${ }^{1,2}$, Yuichi Yamaguchi ${ }^{1,3}$ and Hiroshi Tomoda ${ }^{1,2}$ \\ A new compound designated as clonoamide was isolated from a culture broth of the fungus Clonostachys sp. BF-0131 by \\ solvent extraction, Diaion HP20 column chromatography, octadecylsilyl column chromatography and preparative HPLC as an \\ inhibitor of sterol 0 -acyltransferase (SOAT). The structure of clonoamide was elucidated as 2-oxo-9E,11E-tridecandienyl \\ acetamide by various spectral analyses including NMR. The compound inhibited SOAT1 and SOAT2 isozymes with IC 50 values of

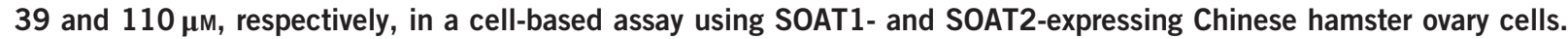 \\ The Journal of Antibiotics (2015) 68, 615-619; doi:10.1038/ja.2015.37; published online 22 April 2015
}

\section{INTRODUCTION}

Sterol O-acyltransferase (SOAT, also known as acyl-CoA:cholesterol acyltransferase, EC 2.4.1.26), an endoplasmic reticulum membrane protein, catalyzes the synthesis of cholesteryl ester (CE) from free cholesterol and long-chain fatty acyl-CoA. SOAT has been considered as a potential target for post-statin drug development. Although statins, inhibitors of 3-hydroxy-3-methylglutaryl coenzyme A reductase, have been clinically used as powerful cholesterol-lowering agents, the risk of complications and death from cardiovascular events by statin treatment is reduced by only $30 \% .{ }^{1}$ Recent molecular biological studies revealed the existence of two distinct SOAT isozymes in mammals, SOAT1 and SOAT2. ${ }^{2-5}$ SOAT1 is ubiquitously expressed in almost all tissues and cells, such as sebaceous glands, steroidogenic tissues and macrophages, whereas SOAT2 is expressed predominantly in the liver (hepatocytes) and intestine. ${ }^{4}$ In the 2000s, the development of three SOAT inhibitors (avasimibe, ${ }^{6}$ pactimibe ${ }^{7}$ and $\mathrm{K}-604^{8}$ ) failed in clinical trials. The first two inhibitors inhibited both SOAT1 and SOAT2 (dual-type inhibitors), while the last one selectively inhibited SOAT1 (SOAT1-selective-type inhibitor). After that, several lines of evidence $^{9-11}$ indicated that SOAT2 will be a promising target for poststatin drug development. ${ }^{12}$ Accordingly, we have focused on the discovery of SOAT2-selective inhibitors. ${ }^{13}$

During our screening for SOAT2 inhibitors from microorganisms, ${ }^{14}$ a new compound named clonoamide (Figure 1) was isolated from the culture broth of Clonostachys sp. BF-0131 in a cell-based assay using SOAT2-expressing Chinese hamster ovary (SOAT2-CHO) cells. Unfortunately, the compound was found to inhibit both SOAT1 and SOAT2 moderately. In this study, the fermentation, isolation, structural elucidation and biological properties of clonoamide are described.

\section{RESULTS}

Fermentation

Fungal strain BF-0131 was isolated from a soil sample collected at Arisugawanomiya Memorial Park in Tokyo, Japan. In a BLAST search, the rDNA sequence of the internal transcribed spacer region showed high levels of similarity to the genus Clonostachys. Therefore, the producing strain was named Clonostachys sp. BF-0131. The slant culture of the strain grown on $2.4 \%$ potato dextrose agar (Becton, Dickinson and Company, Franklin Lakes, NJ, USA) was inoculated into a 500-ml Erlenmeyer flask containing $100 \mathrm{ml}$ of seed medium (2.4\% potato dextrose broth (Becton, Dickinson and Company) and $0.10 \%$ agar, $\mathrm{pH} 6.0$ ). The flask was shaken on a rotary shaker at $27^{\circ} \mathrm{C}$ for 3 days. The seed culture $(3.0 \mathrm{ml})$ was inoculated into a culture bottle containing the production medium ( $50 \mathrm{~g}$ of Italian rice (Japan Europe Trading Co. Ltd., Tokyo, Japan), 1.2\% potato dextrose broth, $1.0 \%$ malt extract, $1.0 \%$ glucose and $0.050 \%$ peptone, $\mathrm{pH} 6.0$ ). The fermentation was carried out under static conditions at $27^{\circ} \mathrm{C}$ for 14 days.

\section{Isolation}

The 14-day-old culture broth $(1.5 \mathrm{~kg})$ of the fungus was treated with $70 \% \mathrm{EtOH}$ (5.01). After the mixture had been filtered and concentrated to remove $\mathrm{EtOH}$, the residual aqueous solution $(900 \mathrm{ml})$ was applied to a Diaion HP20 column ( $150 \mathrm{ml}$; Mitsubishi Chemical, Tokyo, Japan), and materials were eluted stepwise with $\mathrm{H}_{2} \mathrm{O}$ and $\mathrm{MeOH}(300 \mathrm{ml}$ each). The $\mathrm{MeOH}$ fraction including the active principle was concentrated under reduced pressure to give a brown material $(1.3 \mathrm{~g})$. This material was dissolved in a small amount of $\mathrm{MeOH}$ and applied to an octadecylsilyl column (39 g; Fuji Silysia Chemical, Aichi, Japan). Materials were eluted stepwise with 0, 20, 40, 60, 80 and $100 \% \mathrm{CH}_{3} \mathrm{CN}$ (100 $\mathrm{ml}$ each). The $80 \% \mathrm{CH}_{3} \mathrm{CN}$ fraction

\footnotetext{
${ }^{1}$ Graduate School of Pharmaceutical Sciences, Kitasato University, Tokyo, Japan; ${ }^{2}$ School of Pharmaceutical Sciences, Kitasato University, Tokyo, Japan and ${ }^{3}$ Chugai Pharmaceutical Co., Ltd, Tokyo, Japan

${ }^{4}$ These authors contributed equally to this work.

Correspondence: Professor H Tomoda, Graduate School of Pharmaceutical Sciences, Kitasato University, 5-9-1 Shirokane, Minato-ku, Tokyo 108-8641, Japan.

E-mail: tomodah@pharm.kitasato-u.ac.jp

Received 15 February 2015; revised 3 March 2015; accepted 16 March 2015; published online 22 April 2015
} 
including the active principle was concentrated under reduced pressure to give a brown material $(46 \mathrm{mg})$. Clonoamide was finally purified by preparative HPLC under the following conditions: column, PEGASIL ODS SP100, $20 \times 250 \mathrm{~mm}$ (Senshu Scientific Co., Tokyo, Japan); mobile phase, 35 -min gradient from $70 \% \mathrm{CH}_{3} \mathrm{CN}$ to $80 \%$ $\mathrm{CH}_{3} \mathrm{CN}$; detection, $\mathrm{UV}$ at $210 \mathrm{~nm}$; flow rate, $8.0 \mathrm{ml} \mathrm{min}^{-1}$. Under these conditions, clonoamide was eluted as a peak with a retention time of $28 \mathrm{~min}$. The fraction was concentrated under reduced pressure to give pure clonoamide $(4.6 \mathrm{mg})$ as a white powder.

\section{Structural elucidation of clonoamide}

The physico-chemical properties of clonoamide are summarized in Table 1 . The molecular formula was determined to be $\mathrm{C}_{15} \mathrm{H}_{25} \mathrm{NO}_{2}$ on the basis of HR-FAB-MS measurement. The UV spectrum of clonoamide had an absorption maximum at $225 \mathrm{~nm}$. The IR spectrum showed the absorption maxima at 3311, 1711 and $1654 \mathrm{~cm}^{-1}$, suggesting the presence of amino, ketone and amide moieties, respectively. The ${ }^{13} \mathrm{C}$ NMR spectrum (in $\mathrm{CDCl}_{3}$ ) showed 15 resolved signals, which were classified by the DEPT spectrum into two methyl carbons, $7 s p^{3}$ methylene carbons including one methylene carbon connected to a hetero atom, $4 s p^{2}$ methine carbons and two quaternary carbons including carbonyl and ketone carbons. The connectivity of proton and carbon atoms was established by the HMQC spectrum, as shown in Table 2. Analysis of the ${ }^{1} \mathrm{H}-{ }^{1} \mathrm{H}$ COSY spectrum gave the two partial structures I (C-1 to NH) and II (C-3 to $\mathrm{C}-13)$ drawn as the bold lines in Figure 2. Regarding the stereochemistry of the conjugated double bonds in II, the coupling constants of $9-\mathrm{H}(14.0 \mathrm{~Hz}), 10-\mathrm{H}(14.0 \mathrm{~Hz}), 11-\mathrm{H}(14.0 \mathrm{~Hz})$ and $12-\mathrm{H}(14.0 \mathrm{~Hz})$ indicated that they are assigned as $9 E$ and $11 E$. Analysis of the ${ }^{1} \mathrm{H}-{ }^{13} \mathrm{C}$ long-range couplings of ${ }^{2} \mathrm{~J}$ and ${ }^{3} \mathrm{~J}$ observed in the HMBC experiments gave the following information. The cross peaks from $1-\mathrm{H}_{2}(\delta 4.42)$, $3-\mathrm{H}_{2}\left(\delta\right.$ 2.43) and $4-\mathrm{H}_{2}(\delta 1.61)$ to $\mathrm{C}-2$ ( $\delta$ 205.5) and from $3-\mathrm{H}_{2}$ to C-1 ( $\delta$ 49.2) indicated the presence of a 1-amino-2-oxo- $9 E$, $11 E$-tridecadiene moiety containing the partial structures I and II. Furthermore, the cross peaks from $1-\mathrm{H}_{2}$ and $2^{\prime}-\mathrm{H}_{3}(\delta$ 2.04) to $\mathrm{C}-1^{\prime}(\delta$ 170.0) supported that the amino residue was acetylated. Taking these findings together, the structure of clonoamide was elucidated as 2-oxo-9E,11E-tridecandienyl acetamide, which fulfilled the molecular formula and the degrees of unsaturation.

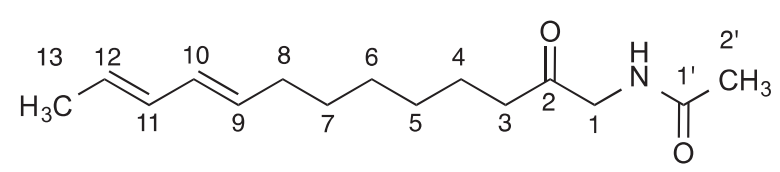

Figure 1 Structure of clonoamide.

Table 1 Physico-chemical properties of clonoamide

\begin{tabular}{lc}
\hline Appearance & White powder \\
Molecular weight & 251 \\
Melecular formula & $\mathrm{C}_{15} \mathrm{H}_{25} \mathrm{NO}_{2}$ \\
HR-FAB-MS $(\mathrm{m} / \mathrm{z})$ & \\
Calcd & $274.1765(\mathrm{M}+\mathrm{Na})^{+}$ \\
$\quad$ Found & $274.1783(\mathrm{M}+\mathrm{Na})^{+}$ \\
$U V \lambda_{\max }^{\operatorname{MeH}}(\log \varepsilon)$ & $225(4.0)$ \\
$\mathrm{IR} \nu_{\max }^{\mathrm{KBr}} \mathrm{cm}^{-1}$ & $3311,2921,2849,1711,1654,1561,1432$ \\
\hline
\end{tabular}

The Journal of Antibiotics

\section{Biological properties}

Inhibition of CE synthesis in SOAT1 and SOAT2-CHO cells. The effect of clonoamide on SOAT1 and SOAT2 isozymes was evaluated in a cell-based assay by using SOAT1- and SOAT2-CHO cells. As shown in Figure 3a, clonoamide dose dependently inhibited CE synthesis in both SOAT1- and SOAT2-CHO cells with $\mathrm{IC}_{50}$ values of 39 and $110 \mu \mathrm{M}$, respectively. It showed no cytotoxic effect at $120 \mu \mathrm{m}$ by the MTT assay.

To confirm the inhibitory activity against SOAT isozymes, the effect of clonoamide on SOAT1 and SOAT2 was investigated in an enzyme assay by using microsomal fractions prepared from the respective cells. As shown in Figure 3b, clonoamide inhibited SOAT1 and SOAT2 activities with $\mathrm{IC}_{50}$ values of 37 and $130 \mu \mathrm{M}$, respectively. These results are consistent with those in a cell-based assay.

Inhibition of CE synthesis in mouse peritoneal macrophages. Inhibition of SOAT1 activity by clonoamide was confirmed in our established assay by using mouse peritoneal macrophages, which exclusively express SOAT1. As shown in Figure 3c, clonoamide inhibited CE synthesis with $\mathrm{IC}_{50}$ value of $16 \mu \mathrm{m}$ and showed no cytotoxic effect at $120 \mu \mathrm{M}$ by the alamar blue assay.

Antimicrobial activity. No antimicrobial activity of clonoamide $(10 \mu \mathrm{g}$ per paper disk) against Bacillus subtilis, Staphylococcus aureus, Micrococcus luteus, Escherichia coli, Pseudomonas aeruginosa and Candida albicans was observed by the agar diffusion assay using paper disks.

Table $2{ }^{1} \mathrm{H}$ and ${ }^{13} \mathrm{C}$ NMR chemical shifts of clonoamide

\begin{tabular}{lcc}
\hline Position & $\delta_{C}\left(\right.$ p.p.m.) ${ }^{\mathrm{a}}$, multi & $\delta_{H}$ (p.p.m.) ${ }^{\mathrm{b}}$, multi, J in Hz \\
\hline 1 & $49.2, \mathrm{t}$ & $4.42, \mathrm{~d}, 4.5$ \\
2 & $205.5, \mathrm{~s}$ & - \\
3 & $40.3, \mathrm{t}$ & $2.43, \mathrm{t}, 8.0$ \\
4 & $23.6, \mathrm{t}$ & $1.61, \mathrm{~m}$ \\
5 & $29.1, \mathrm{t}$ & $1.28, \mathrm{~m}$ \\
6 & $28.7, \mathrm{t}$ & $1.28, \mathrm{~m}$ \\
7 & $28.9, \mathrm{t}$ & $1.36, \mathrm{~m}$ \\
8 & $32.4, \mathrm{t}$ & $2.03, \mathrm{br} . \mathrm{dd}, 6.5,14.0$ \\
9 & $131.8, \mathrm{~d}$ & $5.52, \mathrm{ddd}, 6.5,6.5,14.0$ \\
10 & $131.6, \mathrm{~d}$ & $6.01, \mathrm{dd}, 12.0,14.0$ \\
11 & $130.4, \mathrm{~d}$ & $5.98, \mathrm{dd}, 12.0,14.0$ \\
12 & $126.8, \mathrm{~d}$ & $5.57, \mathrm{dq}, 7.3,14.0$ \\
13 & $17.9, \mathrm{q}$ & $1.72, \mathrm{~d}, 7.3$ \\
$1^{\prime}$ & $170.0, \mathrm{~s}$ & - \\
$2^{\prime}$ & $22.9, \mathrm{q}$ & $2.04, \mathrm{~s}$ \\
$\mathrm{NH}$ & - & $6.23, \mathrm{br} . \mathrm{s}$ \\
\hline
\end{tabular}

${ }^{1} \mathrm{H}$ and ${ }^{13} \mathrm{C}$ NMR spectra were obtained at 600 and $150 \mathrm{MHz}$, respectively and recorded in

${ }^{\mathrm{a} C h e m i c a l}$ shifts are shown with reference to $\mathrm{CDCl}_{3}$ as $\delta 77.0$.

${ }^{b}$ Chemical shifts are shown with reference to $\mathrm{CDCl}_{3}$ as $\delta 7.26$.

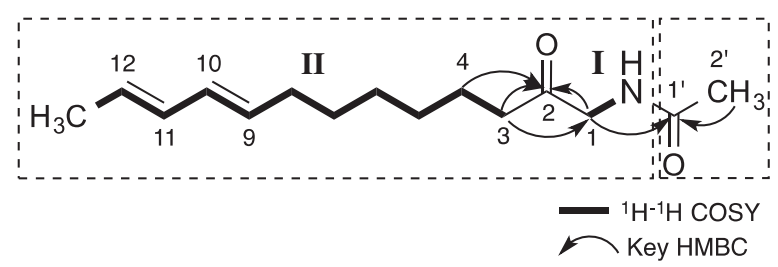

Figure 2 Key cross peaks observed in ${ }^{1} \mathrm{H}-{ }^{1} \mathrm{H}$ COSY and ${ }^{1} \mathrm{H}-{ }^{13} \mathrm{C}$ HMBC experiments of clonoamide. 

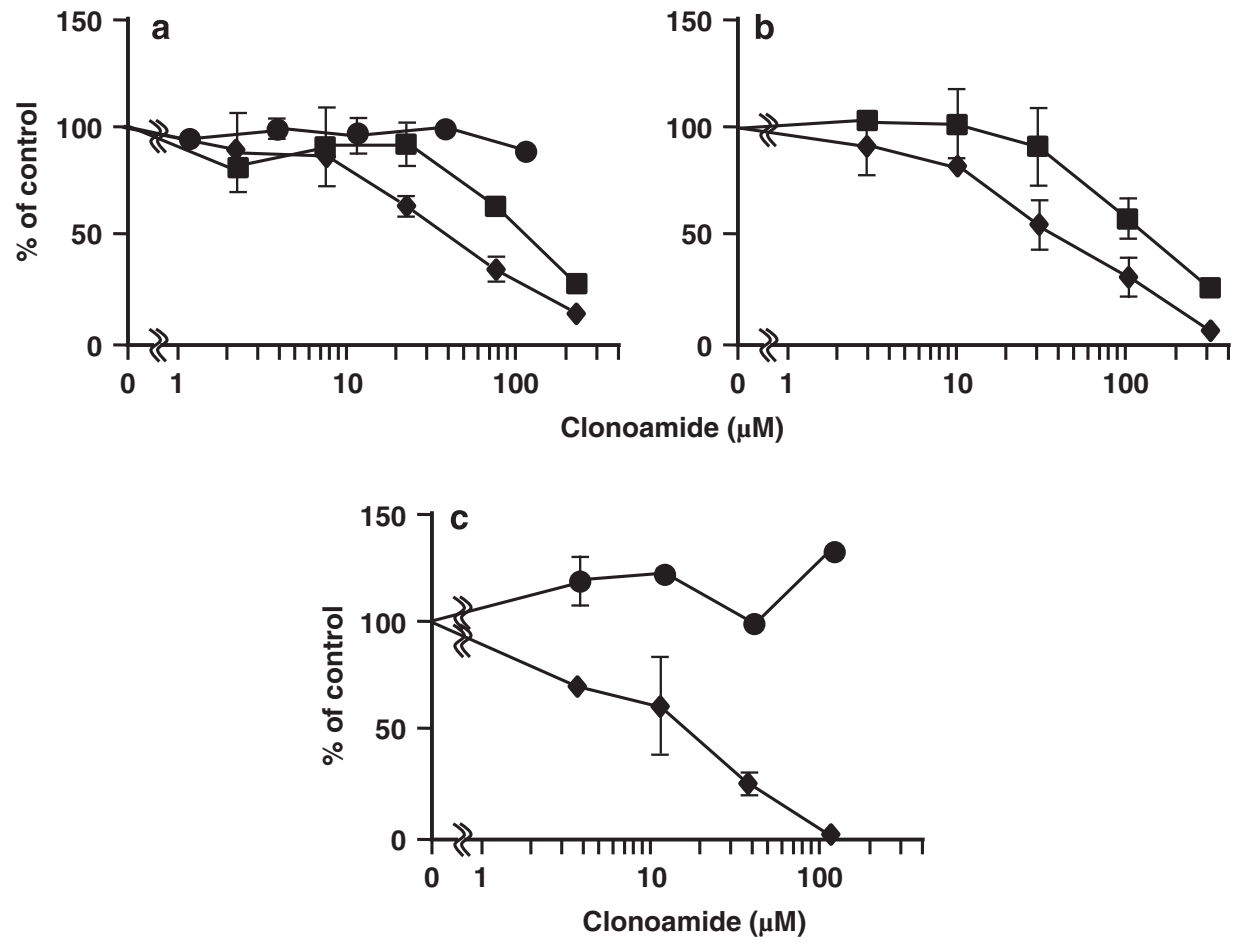

Figure 3 Effects of clonoamide on cholesteryl ester synthesis in (a) SOAT1- and SOAT2-CHO cells, (b) microsomes prepared from SOAT1- and SOAT2-CHO cells and (c) mouse peritoneal macrophages. SOAT1 (a and $\mathbf{b})$ and CE (c) ( $)$, SOAT2 ( $\mathbf{\square})$ and cell viability ( $\bullet$ ).

\section{DISCUSSION}

Clonoamide, produced by the fungus Clonostachys sp. BF-0131, was first discovered as a moderate inhibitor of CE synthesis in SOAT2$\mathrm{CHO}$ cells. From its selectivity test in inhibition toward the two isozymes, the compound inhibited CE synthesis in both SOAT1-( $\mathrm{IC}_{50}$, $39 \mu \mathrm{M})$ and SOAT2-CHO cells $\left(\mathrm{IC}_{50}, 110 \mu \mathrm{M}\right)$, as shown in Figure 3a. Furthermore, good consistent inhibition by the compound was observed in SOAT1 $\left(\mathrm{IC}_{50}, 37 \mu \mathrm{M}\right)$ and SOAT2 $\left(\mathrm{IC}_{50}, 130 \mu \mathrm{M}\right)$ enzyme assays (Figure $3 \mathrm{~b}$ ). These data indicated that the target molecules of clonoamide are SOAT isozymes, although it appears to prefer SOAT1 to SOAT2. Inhibition of SOAT1 by the compound $\left(\mathrm{IC}_{50}, 16 \mu \mathrm{M}\right)$ was confirmed in the assay using intact mouse peritoneal macrophages (Figure 3c).

The structure of clonoamide was completely elucidated. Chemically synthetic 1 -acetamide-2-tridecanone ${ }^{15}$ and 1 -acetamidetridecane, ${ }^{16}$ structurally related to clonoamide, are already known, but the biological activities have not been reported. In this study, clonoamide was found to inhibit SOAT1 and SOAT2 isozymes. A number of synthetic SOAT inhibitors were reported. One of the important groups is an amide type, such as CI-976, ${ }^{17}$ HL- $004^{18}$ and F-12511. ${ }^{19}$ They consist of an amide core with a long acyl chain. Therefore, clonoamide can be classified into this type. Our group re-evaluated the selectivity of known SOAT inhibitors toward the two isozymes in cell-based assay or enzyme assay by using SOAT1- and SOAT2-CHO cells. ${ }^{14,20}$ Through the experiments, we classified SOAT inhibitors into three types from the selective index (SI) values, which are defined as log $\left(\mathrm{IC}_{50}\right.$ for $\mathrm{SOAT}_{1 / \mathrm{IC}_{50}}$ for SOAT2); ${ }^{13}$ inhibitors with $\mathrm{SI}>+1$, $+1 \geqq \mathrm{SI} \geqq-1$ and $-1>\mathrm{SI}$ are SOAT2-selective type, dual type and SOAT1-selective type, respectively. Most inhibitors including avasimibe and pactimibe belong to the dual type. Synthetic K-604 and Wu$\mathrm{V}-23$ and fungal beauveriolides I and $\mathrm{III}^{21}$ belong to the SOAT1selective type. Pyripyropenes are a rare example belonging to the
SOAT2-selective type. According to the definition, clonoamide with SI of -0.54 is classified as a dual-type inhibitor. Our group will continue to search for SOAT2-selective inhibitors of microbial origin, which are expected to have potential as post-statin drugs. ${ }^{12,13}$

\section{MATERIALS AND METHODS}

General

Various NMR spectra were obtained using an INOVA $600 \mathrm{MHz}$ spectrometer (Agilent Technologies, Santa Clara, CA, USA). FAB-MS spectra were recorded on a mass spectrometer (JMS-700 Mstation; JEOL, Tokyo, Japan). UV spectra were recorded on a spectrophotometer (Beckman DU640 spectrophotometer; Beckman Coulter, Inc., Fullerton, CA, USA). IR spectra were recorded on a Fourier transform infrared spectrometer (FT-710; Horiba Ltd, Kyoto, Japan).

\section{Material}

$\left[1-{ }^{14} \mathrm{C}\right]$ Oleic acid $\left(1.85 \mathrm{GBq}_{\mathrm{mmol}}{ }^{-1}\right)$ and $\left[1-{ }^{14} \mathrm{C}\right]$ oleoyl-coenzyme A $(1.85$ GBq $\mathrm{mmol}^{-1}$ ) were purchased from PerkinElmer (Waltham, MA, USA). Fetal bovine serum was purchased from Biowest (Nuaille, France). Dulbecco's modified Eagle's medium and Hank's buffered salt solution were purchased from Nissui Pharmaceutical Co. (Tokyo, Japan). GIT medium was from Nippon Seiyaku Co. (Tokyo, Japan). Penicillin (10000 units $\mathrm{ml}^{-1}$ ), streptomycin $\left(10000 \mathrm{mg} \mathrm{ml}^{-1}\right)$ and glutamine $(200 \mathrm{~mm})$ solution were from Invitrogen (Carlsbad, CA, USA). Phosphatidylcholine, phosphatidylserine, dicetylphosphate, cholesterol, Ham's F-12 medium, fatty acid-free bovine serum albumin and MEM vitamin solution were purchased from Sigma-Aldrich (St Louis, MO, USA). Geneticin (G-418 sulfate) was purchased from Life Technologies Corporation (Carlsbad, CA, USA).

\section{Cell culture}

Two cell lines, CHO cells expressing SOAT1 and SOAT2 isozymes of African green monkey (SOAT1- and SOAT2-CHO cells, respectively), ${ }^{22}$ were kind gifts from Dr Lawrence L. Rudel (Wake Forest University, Winston Salem, NC, USA) and were cultured by a method described previously. ${ }^{20}$ 
Assays for SOAT1 and SOAT2 activities using SOAT1- and SOAT2CHO cells

Assays for SOAT1 and SOAT2 activities using SOAT1- and SOAT2-CHO cells were carried out by our established method. ${ }^{21}$ Briefly, SOAT1- or SOAT2-CHO cells $\left(1.25 \times 10^{5}\right.$ cells $)$ were cultured in each well of a 48 -well plastic microplate (Corning Co., Corning, NY, USA) in $250 \mu \mathrm{l}$ of medium A containing Ham's F-12 medium supplemented with $10 \%$ heat-inactivated fetal bovine serum, MEM vitamins, penicillin (100 units $\mathrm{ml}^{-1}$ ), streptomycin (100 units $\mathrm{ml}^{-1}$ ) and geneticin $\left(300 \mu \mathrm{g} \mathrm{ml}^{-1}\right)$ and allowed to recover overnight at $37^{\circ} \mathrm{C}$ in $5.0 \%$ $\mathrm{CO}_{2}$. The assays were carried out under at least $80 \%$ confluent cell conditions. Following overnight recovery, a test sample (in $2.5 \mu \mathrm{l}$ of $\mathrm{MeOH}$ ) and $\left[{ }^{14} \mathrm{C}\right]$ oleic acid ( $1 \mathrm{nmol}, 1.85 \mathrm{kBq}$ in $5.0 \mu \mathrm{l}$ of $10 \% \mathrm{EtOH} /$ phosphate-buffered saline) were added to each well of the culture. After $6 \mathrm{~h}$ of incubation at $37^{\circ} \mathrm{C}$ in $5.0 \% \mathrm{CO}_{2}$, the cells in each well were washed twice with phosphate-buffered saline and lysed by adding $0.25 \mathrm{ml}$ of $10 \mathrm{~mm}$ Tris- $\mathrm{HCl}(\mathrm{pH} 7.5)$ containing $0.10 \%(\mathrm{w} / \mathrm{v})$ SDS, and the cellular lipids were extracted by the method of Bligh and Dyer. ${ }^{23}$ After concentrating the organic solvent, the total lipids were separated on a TLC plate (silica gel F254, 0.5 mm thick, Merck, Kenilworth, NJ, USA), which was analyzed with a bioimaging analyzer (FLA-7000; Fujifilm, Tokyo, Japan) to measure the amount of $\left[{ }^{14} \mathrm{C}\right] \mathrm{CE}$. The $\mathrm{IC}_{50}$ value was defined as a drug concentration causing $50 \%$ inhibition of biological activity.

\section{Preparation of microsomes from SOAT1- or SOAT2-CHO cells} SOAT1- or SOAT2-CHO cells $\left(2 \times 10^{8}\right.$ cells $)$ were homogenized in $10 \mathrm{ml}$ of cold buffered sucrose solution ( $\mathrm{pH} 7.2$, hereafter referred to as buffer A, $100 \mathrm{~mm}$ sucrose, $50 \mathrm{~mm} \mathrm{KCl}, 40 \mathrm{~mm} \mathrm{KH}_{2} \mathrm{PO}_{4}$ and $30 \mathrm{~mm}$ EDTA) including protease inhibitors $\left(5.0 \mathrm{mg} \mathrm{ml}^{-1}\right.$ aprotinin, $5.0 \mathrm{mg} \mathrm{ml}^{-1}$ leupeptin, $5.0 \mathrm{mg} \mathrm{ml}^{-1}$ pepstatin and $0.50 \mathrm{~mm}$ phenylmethanesulfonyl fluoride) in a teflon homogenizer. The microsomal fraction was pelleted by centrifugation at $100000 \mathrm{~g}$ for $1 \mathrm{~h}$ at $4^{\circ} \mathrm{C}$, resuspended in the same buffer at a concentration of $5.0 \mathrm{mg}$ protein $\mathrm{ml}^{-1}$ and stored at $-80^{\circ} \mathrm{C}$ until use.

\section{Assay for SOAT activity in microsomes prepared from SOAT1- and SOAT2-CHO cells}

SOAT1 and SOAT2 activities were determined by using microsomes prepared as described above as the enzyme source. ${ }^{24}$ Briefly, an assay mixture containing $2.5 \mathrm{mg} \mathrm{ml}^{-1}$ fatty acid-free bovine serum albumin in buffer $\mathrm{A}$ and $\left[{ }^{14} \mathrm{C}\right]$ oleoyl$\mathrm{CoA}(3.7 \mathrm{kBq})$ together with a sample (added as a $5.0 \mu \mathrm{l} \mathrm{MeOH}$ solution), and the SOAT1 or SOAT2 microsomal fraction $(150$ or $10 \mu \mathrm{g}$ of protein, respectively) in a total volume of $200 \mu \mathrm{l}$ were incubated at $37^{\circ} \mathrm{C}$ for $5 \mathrm{~min}$. The reaction was started by adding $\left[{ }^{14} \mathrm{C}\right]$ oleoyl-CoA, and stopped by adding $1.2 \mathrm{ml}$ of $\mathrm{CHCl}_{3}: \mathrm{MeOH}(2: 1)$. The total lipids were extracted to measure the radioactivity of $\left[{ }^{14} \mathrm{C}\right] \mathrm{CE}$ according to the same method as described above.

\section{MTT assay}

Assay for cytotoxic activity using $\mathrm{CHO}$ cells was carried out by our established method. ${ }^{25}$ Briefly, cytotoxicity of a sample to $\mathrm{CHO}$ cells was measured by the colorimetric assay on MTT. CHO cells $\left(5.0 \times 10^{4}\right.$ cells in $\left.100 \mu \mathrm{l}\right)$ were added to each well of a 96-well microplate. A sample $(1.0 \mu \mathrm{l}$ in $\mathrm{MeOH})$ was added to each well, and the cells were incubated for $12 \mathrm{~h}$ at $37^{\circ} \mathrm{C}$. MTT $(10 \mu \mathrm{l}$ of $5.5 \mathrm{mg} \mathrm{ml}^{-1}$ stock solution) and a cell lysate solution $(90 \mu \mathrm{l}, 40 \% \mathrm{~N}$, $\mathrm{N}$-dimethylformamide, $20 \% \mathrm{SDS}, 2.0 \% \mathrm{CH}_{3} \mathrm{COOH}$ and $0.030 \% \mathrm{HCl}$ ) were added to each well, and the microplate was shaken for $2 \mathrm{~h}$. The OD of each well was measured at $540 \mathrm{~nm}$ by using a microtiter-plate reader (Elx 808; BioTek Instruments, Winooski, VT, USA).

\section{Assay for CE synthesis in mouse peritoneal macrophages}

The assay for the synthesis of neutral lipid from $\left[{ }^{14} \mathrm{C}\right]$ oleic acid was carried out according to a previously described method. ${ }^{26}$ Briefly, mouse peritoneal macrophages $\left(5.0 \times 10^{5}\right.$ cells in $250 \mu \mathrm{l}$ of medium B (containing Dulbecco's modified Eagle's medium supplemented with $8.0 \%(\mathrm{v} / \mathrm{v})$ lipoprotein-deficient serum, penicillin (100 units $\left.\mathrm{ml}^{-1}\right)$ and streptomycin $\left(100 \mathrm{mg} \mathrm{ml}^{-1}\right)$ ) were cultured in each well of a 48-well plastic microplate with a test compound (in $2.5 \mu \mathrm{l}$ of $\mathrm{MeOH})$ and liposomes $(10.0 \mu \mathrm{l}, 1.0 \mu \mathrm{mol}$ phosphatidylcholine, $1.0 \mu \mathrm{mol}$ phosphatidylserine, $0.20 \mu \mathrm{mol}$ dicetylphosphate and $1.5 \mu \mathrm{mol}$ cholesterol, suspended in $1.0 \mathrm{ml}$ of $0.30 \mathrm{M}$ glucose) together with $\left[{ }^{14} \mathrm{C}\right]$ oleic acid $(5.0 \mu \mathrm{l}(1.85 \mathrm{kBq})$ in $10 \%$ ethanol/phosphate-buffered saline solution). Following $14 \mathrm{~h}$ of incubation, cellular lipids were extracted to measure the radioactivity of $\left[{ }^{14} \mathrm{C}\right] \mathrm{CE}$ according to the same method as described above.

\section{Alamar blue assay}

The cytotoxicity of clonoamide to mouse macrophages after $14 \mathrm{~h}$ of incubation was measured by using alamar blue reagent according to the established method. $^{23}$

\section{Antimicrobial activity}

Antimicrobial activity of a sample against six species of microorganisms was measured by the agar diffusion method by using paper disks. Media for microorganisms were as follows: nutrient agar (Sanko Junyaku Co., Ltd, Tokyo, Japan) for B. subtilis PCI219, S. aureus FDA209P, M. luteus KB212, E. coli JM109 and $P$. aeruginosa IFO12689, and a medium composed of $1.0 \%$ glucose, $0.50 \%$ yeast extract and $0.80 \%$ agar for C. albicans ATCC 90029 . A paper disk (i.d. $6 \mathrm{~mm}$; Toyo Roshi Kaisha, Tokyo, Japan) containing a sample (10 $\mu \mathrm{g})$ was placed on the agar plate. Bacteria were incubated at $37^{\circ} \mathrm{C}$ for $24 \mathrm{~h}$. C. albicans was incubated at $27^{\circ} \mathrm{C}$ for $48 \mathrm{~h}$. Antimicrobial activity was expressed as the diameter $(\mathrm{mm})$ of the inhibitory zone.

\section{ACKNOWLEDGEMENTS}

We wish to thank Ms Noriko Sato and Dr Kenichiro Nagai (School of Pharmaceutical Sciences, Kitasato University) for measurements of NMR spectra and MS data. This work was supported by a Grant-in-aid for Scientific Research (A) 26253009 from the Ministry of Education, Culture, Sports, Science and Technology, Japan (to HT).

1 Libby, P. The forgotten majority: unfinished business in cardiovascular risk reduction. J. Am. Coll. Cardiol. 46, 1225-1228 (2005).

2 Chang, C. C., Huh, H. Y., Cadigan, K. M. \& Chang, T. Y. Molecular cloning and functional expression of human acyl-coenzyme A: cholesterol acyltransferase cDNA in mutant Chinese hamster ovary cells. J. Biol. Chem. 268, 20747-20755 (1993).

3 Anderson, R. A. et al. Identification of a form of acyl-CoA:cholesterol acyltransferase specific to liver and intestine in nonhuman primates. J. Biol. Chem. 273, 26747-26754 (1998).

4 Cases, S. et al. ACAT-2, a second mammalian acyl-CoA:cholesterol acyltransferase. Its cloning, expression, and characterization. J. Biol. Chem. 273, 26755-26764 (1998).

5 Oelkers, P., Behari, A., Cromley, D., Billheimer, J. T. \& Sturley, S. L. Characterization of two human genes encoding acyl coenzyme A:cholesterol acyltransferase-related enzymes. J. Biol. Chem. 273, 26765-26771 (1998).

6 Lee, H. T. et al. Inhibitors of acyl-CoA: cholesterol 0-acyltransferase (ACAT) as hypocholesterolemic agents. Cl-1011: an acyl sulfamate with unique cholesterollowering activity in animals fed noncholesterol-supplemented diets. J. Med. Chem. 39, 5031-5034 (1996).

7 Terasaka, N. et al. ACAT inhibitor pactimibe sulfate (CS-505) reduces and stabilizes atherosclerotic lesions by cholesterol-lowering and direct effects in apolipoprotein E-deficient mice. Atherosclerosis 190, 239-247 (2007).

8 Ikenoya, M. et al. A selective ACAT-1 inhibitor, K-604, suppresses fatty streak lesions in fat-fed hamsters without affecting plasma cholesterol levels. Atherosclerosis 191, 290-297 (2007).

9 Buhman, K. K. et al. Resistance to diet-induced hypercholesterolemia and gallstone formation in ACAT2-deficient mice. Nat. Med. 6, 1341-1347 (2000).

10 Willner, E. L. et al. Deficiency of acyl CoA:choletsterol acyltransferase 2 prevents atherosclerosis in apolipoprotein E-deficient mice. Proc. Natl. Acad. Sci. USA 100, 1262-1267 (2003)

11 Ohshiro, T. et al. Pyripyropene A, an acyl-coenzyme A:cholesterol acyltransferase 2selective inhibitor, attenuates hypercholesterolemia and atherosclerosis in murine models of hyperlipidemia. Artherioscler. Thromb. Vasc. Biol. 31 1108-1115 (2011).

12 Ohshiro, T. \& Tomoda, H. Acyltransferase inhibitors: a patent review (2010-present). Expert Opin. Ther. Pat. 25, 145-158 (2014).

13 Ohshiro, T. \& Tomoda, H. Isoform-specific inhibitors of ACATs: recent advances and promising developments. Future Med. Chem. 3, 2039-2061 (2011).

14 Tomoda, H. \& Ōmura, S. Potential therapeutics for obesity and atherosclerosis: inhibitors of neutral lipid metabolism from microorganisms. Pharmacol. Ther. 115 375-389 (2007).

15 Shrecker, A. W. \& Trail, M. M. Aminoketones. I. The preparation of $\alpha$-aminoketones from Di-t-butyl acetamidomalonate. J. Am. Chem. Soc. 80, 6077-6080 (1958). 
16 Gould, F. E., Johnson, G. S. \& Ferris, A. F. The hydrogenation of nitriles to primary amines. J. Org. Chem. 25, 1658-1660 (1960).

17 O'brian, P. M. et al. Inhibitors of acyl-CoA:cholesterol O-acyltransferase. Synthesis and pharmacological activity of (+/-)-2-dodecyl-alpha-phenyl- $N$-(2,4,6-trimethoxyphenyl)$2 \mathrm{H}$-tetrazole-5-acetamide and structurally related tetrazole amide derivatives. J. Med. Chem. 39, 2354-2366 (1996).

18 Murakami, S., Araki, H., Otomo, S., Nara, Y. \& Yamori, Y. Effects of HL-004, a novel ACAT inhibitor, on cholesterol accumulation and removal in cultured smooth muscle cells from stroke-prone spontaneously hypertensive rats (SHRSP). Life Sci. 56, 509-520 (1995).

19 Junquero, D. et al. Pharmacological profile of $\mathrm{F}$ 12511, (S)-2',3',5'-trimethyl-4'hydroxy-alpha-dodecylthioacetanilide a powerful and systemic acylcoenzyme A: cholesterol acyltransferase inhibitor. Biochem. Pharmacol. 61, 97-108 (2001).

20 Ohshiro, T., Rudel, L. L., Ōmura, S. \& Tomoda, H. Selectivity of microbial acyl-CoA:cholesterol acyltransferase inhibitors toward isozymes. J. Antibiot. 60, 43-51 (2007).
21 Namatame, I., Tomoda, H., Ishibashi, S. \& Ōmura, S. Antiatherogenic activity of fungal beauveriolides, inhibitors of lipid droplet accumulation in macrophages. Proc. Natl. Acad. Sci. USA. 101, 737-742 (2004).

22 Lada, A. T. et al. Identification of ACAT1- and ACAT2-specific inhibitors using a novel, cell-based fluorescence assay: individual ACAT uniqueness. J. Lipid Res. 45, 378-386 (2004)

23 Bligh, E. G. \& Dyer, W. A rapid method of total lipid extraction and purification. Can. J. Biochem. Physiol 37, 911-917 (1959).

24 Field, F. J., Cooper, A. D. \& Erickson, S. K. Regulation of rabbit intestinal acyl coenzyme A-cholesterol acyltransferase in vivo and in vitro. Gastroenterology 83 , 873-880 (1982)

25 Ohte, S. et al. Dinapinones, novel inhibitor of triacylglycerol synthesis in mammalian cells, produced by Penicillium pinophilum FKI-3864. J. Antibiot. 64, 489-494 (2011).

26 Namatame, I., Tomoda, H., Arai, H., Inoue, K. \& Ōmura, S. Complete inhibition of mouse macrophage-derived foam cell formation by triacsin C. J. Biochem. 125, 319-327 (1999) 